\title{
ANALYSIS OF FATAL ELECTRICAL TRAUMAS IN THE REGION OF VARNA FOR A 41-YEAR-LONG PERIOD
}

\author{
Dokov W. V. \\ Department of Forensic medicine, Prof. Paraskiev Stoyanov Medical University of Varna \\ Reviewed by: Assoc. Prof. D. Radoinova, MD, PhD
}

\begin{abstract}
Introduction. Electrotraumatism (ET) is rare to observe, but it presents a significant problem both for public health and forensic medicine. Purpose. The purpose of this study is to identify some features and circumstances typical of ET on the territory of Varna District. Material and methods. Forensic medicine documentation has been examined from 16,780 autopsies for the period 1965-2005 performed at the Chair of Forensic Medicine and Deontology, the Medical University of Varna. The results have been processed by the statistical methods of alternative, variational and graphical analysis. Results. Over the 41-year-long period, a total of $280 \mathrm{ET}$ autopsies have been performed, which accounts for $1.67 \%(\mathrm{p} \pm \Delta 1,5)$ of all autopsies. Lethal injuries by electric current typically occur in young age. Young males prevail. More than half of the events have been domestic ET. In the studied group, the number of accidents caused by high voltage is about the same as the number of accidents caused by low voltage. Suicide by electric current is relatively rare. A forensic medicine expert participated in $99(62.26 \% \mathrm{p} \pm \Delta 9.55)$ of the inspections on the scene of accident. Conclusions. $\mathrm{ET}$ affects mainly young males in domestic ET.
\end{abstract}

Keywords: Electro-traumatism, Varna District

\section{INTRODUCTION}

Electrotraumatism (ET) is rare to observe, but it presents a significant problem both for public health and forensic medicine. Its relatively low incidence is not conducive to major studies due to which there are scarce data on this problem in literature. This prompted us to undertake the present study.

\section{PURPOSE}

The purpose of this study is to identify some features and circumstances typical of ET on the territory of Varna District.

\section{MATERIAL AND METHODS}

Forensic medicine documentation has been examined from 16,780 autopsies for the period 1965-2005 performed at the Chair of Forensic Medicine and Deontology, the Medical University of Varna. The results have been processed by the statistical methods of alternative, variational and graphical analysis.

\section{Address for correspondence:}

W. Dokov, Department of Forensic Medicine, Medical University Prof. Dr. Paraskev Stoyanov, 55 Marin Drinov St, BG-9002 Varna, BULGARIA

e-mail: Dokov@seznam.cz

\section{RESULTS AND DISCUSSION}

Over the 41-year-long period, a total of $280 \mathrm{ET}$ autopsies have been performed, which accounts for $1.67 \%(\mathrm{p} \pm \Delta 1.5)$ of all autopsies. The average age of the deceased from ET is $35.47 \pm 2.91$ years, within the scope of 1 to 83 years. Male gender prevails over the female with $242(86.43 \%$ $\mathrm{p} \pm \Delta 4.22)$ to $38(13.57 \% \mathrm{p} \pm \Delta 9.39)$. The difference in the relative share between males $(\mathrm{M})$ and females $(\mathrm{F})$ is statistically reliable $(\mathrm{p}<0.001)$.

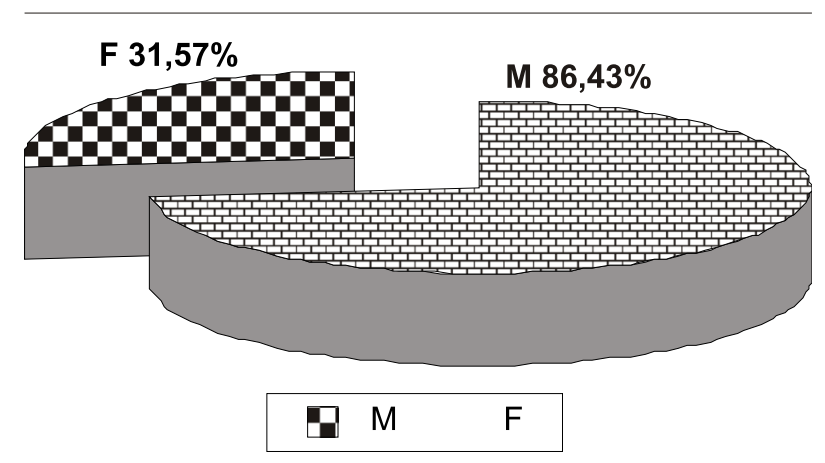

Fig. 1 Distribution by gender of the deceased from electrotrauma.

More than half of the cases are domestic ET (DET): 160 $(57.14 \% \mathrm{p} \pm \Delta 7.67)$, and about $1 / 3$ are labour-related electrotraumas (LET): 86 (30.71\% $\mathrm{p} \pm \Delta 9.75)$. Suicides 
(SC) by electric current are relatively rare to observe: 17 $(6.07 \% \mathrm{p} \pm \Delta 11.35)$

In 18 cases $(6.43 \% \mathrm{p} \pm \Delta 11.33)$, there are no data about the type of the accident on inspection or the autopsy (N/A).

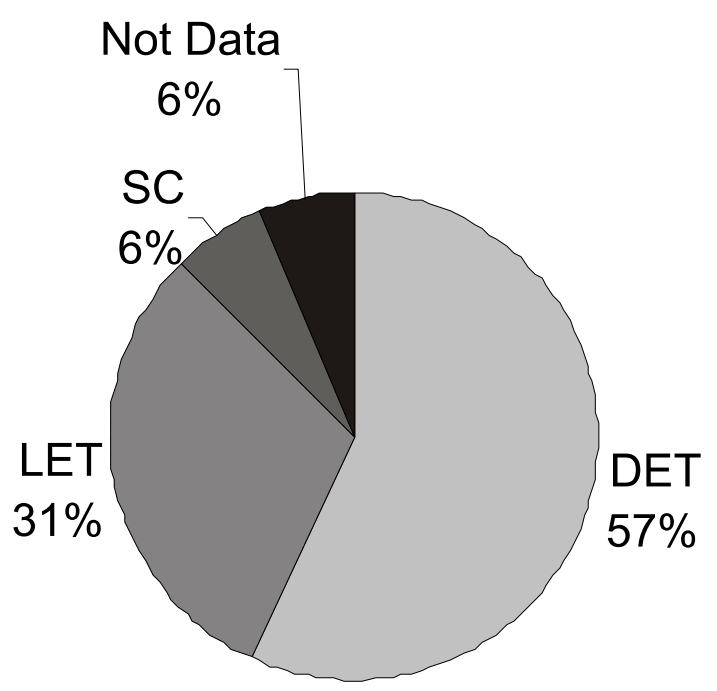

Fig. 2 Structure of ET depending on the type of electrotrauma.

Injuries caused by low voltage $(<220 \mathrm{~V}), 93(33.21 \%$ $\mathrm{p} \pm \Delta 9.57)$, and by high voltage $(>220 \mathrm{~V}), 91 \quad(32.5$ $\mathrm{p} \pm \Delta 9.62)$, are approximately the same number without a significant difference ( $p>0.5)$. In 96 cases ( $34.28 p \pm \Delta 9.49)$ there are no data about the voltage of the electric current at the beginning of the expertise, which impedes the diagnostic process.

A large part of information significant for the forensic-medical diagnosis and expertise can be ascertained as soon as the scene of accident is inspected. Forensic-medical expert participated in 99 inspections $(62.26 \% \mathrm{p} \pm \Delta .55)$ out of a total 159 cases studied by us, but quite a few, 60 (37.74\% $\mathrm{p} \pm \Delta 12.27$ ), were performed in his absence.

Electrotraumas account for 3.1\% (1) respectively 5\% (3), $5.1 \%$ (5) up to $21 \%$ (4) of all cases of burns. Our data have revealed that ET is observed in $1.67 \%$ of all autopsies after violent or non-violent death.

Our study has discovered a characteristic age-related peculiarity. ET affect mainly young people $(x=35.47 \pm 2.91$ years) of working age. There is a peculiar distribution of the cases by gender. We have ascertained that males are mainly affected $(86.43 \% \mathrm{p} \pm \Delta 4.22)$. Similar results are reported by Nursal TZ, et al (2003) and Celik A, et al (2004) according to whom males are affected in $67 \%$ or $95 \%$ of the cases, respectively.

The results of our study show that the prevailing part of ET are domestic or labour-related accident. With results like these, we could not agree more with the recommendations given by Nursal TZ, et al (2003) according to whom prevention, public discussion of the problem and strict observance of the rules when distributing electric power would notably reduce this type of traumatism.

While the data given by Celik A, et al (2004) point to a prevalence of injuries due to electric current of high voltage: $63 \%$, our results show a relatively even distribution of the cases either of high or low voltage. At the other end of the scale are the data given by Byard RW(2003): a very rare occurrence of accidents caused by high voltage.

Our study brings forth a question of pressing interest about the effectiveness of the process of diagnostics and expertise in relation to the data from the inspection of the accident scene. The relatively high percentage of cases $(37.74 \%)$ where a forensic medicine expert was not present on the inspection point to feasible opportunities to increase the speed and quality of expert activities in this direction.

\section{CONCLUSIONS}

Fatal injuries due to electric current are typical of young age.

There is a prevalence of persons of male gender.

More than half of the cases result from domestic electrotraumatism.

The injuries due to high or low voltage current are distributed approximately evenly by number in the group under study.

\section{REFERENCES}

1. Borisov VG, Kashin IuD, Oliunina NA. Deep electrothermal burns Khirurgiia (Mosk). 1995;6 :29-31.

2. Byard RW, Hanson KA, Gilbert JD, James RA, Nadeau J, Blackbourne B, Krous HF. Death due to electrocution in childhood and early adolescence. J Paediatr Child Health. 2003 ;39(1):46-8.

3. Celik A, Ergun O, Ozok G. Pediatric electrical injuries: a review of 38 consecutive patients. $J$ Pediatr Surg. 2004 ;39(8):1233-7.

4. Nursal TZ, Yildirim S, Tarim A, Caliskan K, Ezer A, Noyan T. Burns in southern Turkey: electrical burns remain a major problem. J Burn Care Rehabil. 2003 24(5):309-14.

5. Henckel von Donnersmarck G, Muhlbauer W, Herndl E, Schmidt A. Reconstruction of the cranial vault and soft tissues of the skull after electrotrauma Langenbecks Arch Chir Suppl II Verh Dtsch Ges Chir. 1989;:847-51. 